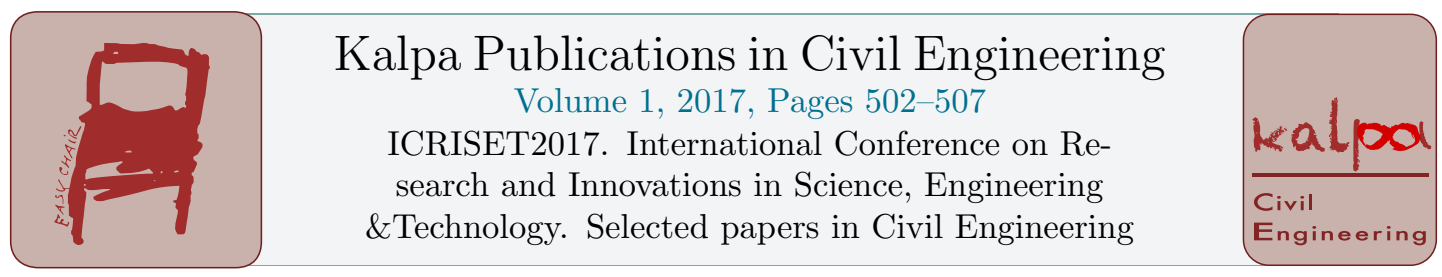

\title{
A Comparative Study of Effectiveness of Steel Plate Shear Wall Patterns in Steel Building
}

\author{
Kavin Y. Patel ${ }^{1,2^{*}}$ and Dipali Y. Patel ${ }^{1 \dagger}$ \\ ${ }^{1}$ Civil Engineering Department, \\ ${ }^{2}$ Chandubhai S. Patel Institute of Technology, (CHARUSAT),Changa, Gujarat, India \\ Kavinpatel85292@gmail.co, dipalipatel.cveCharusat.ac.in
}

\begin{abstract}
Steel buildings prone to lateral loads responds well if provided with SPSW. SPSW is more effective for lateral loads as they are more ductile, lighter and lesser space occupants. SPSW systems are used in high-rise buildings as retrofitting also. Now a days conventional SPSW are more preferred in steel buildings. By keeping the view in mind, an effort has been made to check the effectiveness of different patterns of SPSW. For the same, bare-frame is compared with Conventional SPSW, X-type SPSW and Diagonal SPSW. Strip modelling is used to analyse SPSW in building using ETABS software. The load considered are primary loads and earthquake load as Static coefficient method from IS 1893:2002. The maximum displacement and axial forces are compared to get effective pattern.
\end{abstract}

\section{Introduction}

High-rise buildings are getting popular day by day as there is shortage of land. As the height of building increases lateral forces effects building design by increasing member sections and foundations of building. To overcome this problem there are two ways, either to provide higher sections which is uneconomical or to provide proper system to resist lateral load. Shear wall is main component for resisting lateral loads acting on high-rise building. Being much efficient over any system SPSW has been used widely in steel high-rise structures. Shear wall mainly increase stiffness in building providing them better way to sustain lateral loads [4]. Absorbing much of lateral load acting on structure with their higher moment of inertia in the way of force. SPSW being lighter and thinner they are preferable, as architectural space is increased and more stiffness is added to building. Most effective system of placing shear wall in different panel can reduce higher level of lateral load and provides high stiffness and stability to building. 


\section{Modelling of steel plate shear wall for analysis}

Strip modelling is the best way to analyse steel plate shear (SPSW) wall which has been adapted by many engineers. It is the easy way to analyse SPSW frame [3]. It is assume that strips are under tension field action. Canada, the CAN/CSA-S16-01suggest the following type of modelling of SPSW for the analysis and design. SPSW walls are replaced by strips or truss member in the direction of tension area [1]. There are two ways of modelling using strip model. One method is to divide wall panel into strips placed at constant angle with the horizontal and the second is the multi angle strip model at different angle.

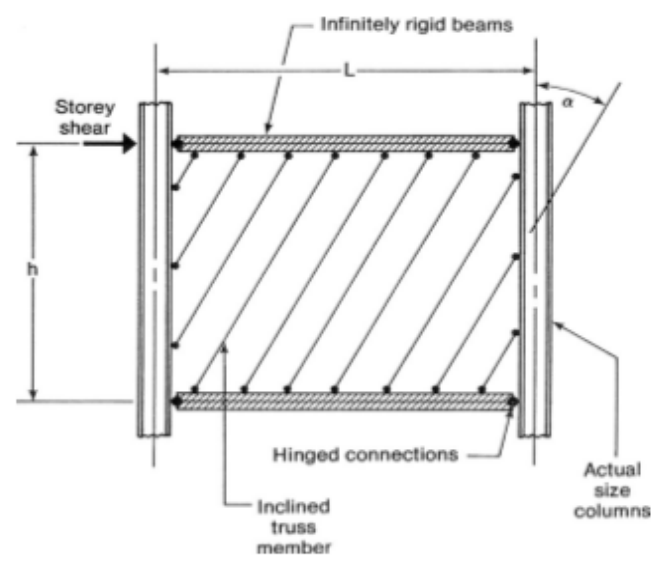

Figure 1 : Diagonal strip modelling

Modelling of steel plate requires 10 strip per wall panel. Angle of inclination for strip must be between $38 \mathrm{o}$ to $45 \mathrm{o}$. Each strip width must be equal to centre to centre distance of two strip provided simultaneously. The connection between strips and column must be kept hinge or pinned. Connection of beam surrounding the strip must be kept pinned to column [2].

Topalakatti and Kinnagi (2014) have carried out "Parametric Study of Steel Frame Building with and without Steel Plate Shear Wall". They have concluded that using SPSW in steel building displacement, axial-force, moments can be reduced.

SPSW being most effective for steel building to resist earthquake load so effort has been made to find most effective pattern. To obtained reduce forces, displacement and figure out best patterns among them.

\section{Structural details}

The following parameters are considered for the study. 


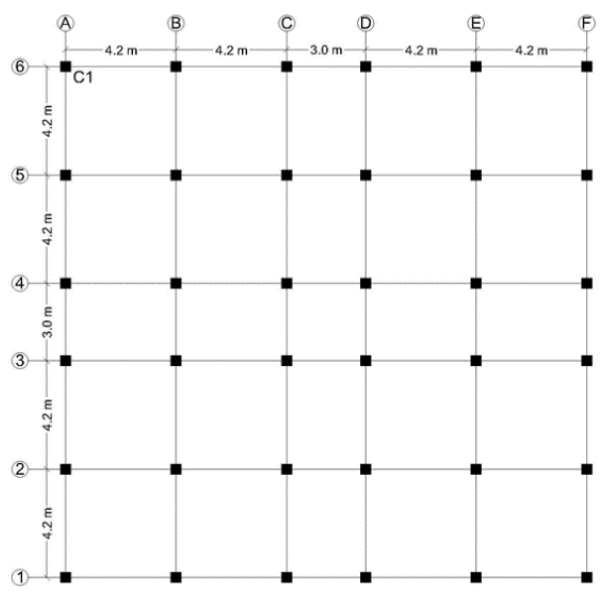

Figure 2 : Plan of $\mathrm{G}+15$ building

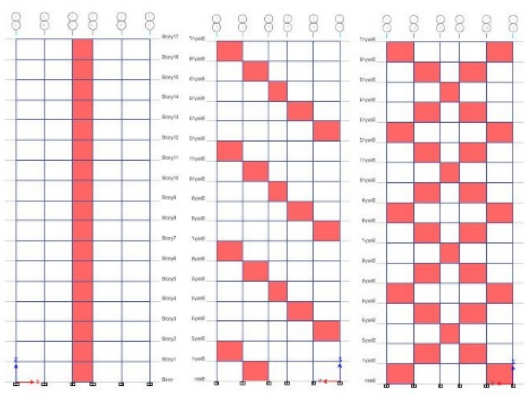

figure 3 : Elevation of Bare-frame, Diagonal and X-type respectively for showing placement of SPSW.

Member specification:-

\subsection{Beam specification}

\begin{tabular}{|c|c|c|}
\hline Beam & steel & SPSW \\
\hline Storey & ISMB & ISMB 300 \\
1 to9 & 300 & \\
\hline Storey & ISMB & ISMB 200 \\
10 to 15 & 200 & \\
\hline
\end{tabular}




\subsection{Column specification}

\begin{tabular}{|r|c|c|}
\hline Col & Steel & SPSW \\
\hline Stor & Tube & Tube \\
ey 1to5 & $750 * 750 * 24$ & $750 * 750 * 24$ \\
\hline Stor & Tube & Tube \\
ey 6to9 & $450 * 450 * 20$ & $450 * 450 * 20$ \\
\hline Stor & Tube & Tube \\
ey 10 to & $300 * 300 * 24$ & $300 * 300 * 24$ \\
\hline
\end{tabular}

For comparing effectiveness in buildings frames column and beam specification has been kept same.

\begin{tabular}{|c|c|c|}
\hline 1 & Type of building & MRSF \\
\hline 2 & Zone & V \\
\hline 3 & Stories & G+15 \\
\hline 4 & Earthquake load resisting & SPSW \\
\hline 5 & Storey height & $3 \mathrm{~m}$ \\
\hline 6 & Foundation depth & $3 \mathrm{~m}$ \\
\hline 7 & Slab thickness & $.15 \mathrm{~m}$ \\
\hline 8 & Width of wall (external) & $.230 \mathrm{~m}$ \\
\hline 9 & Width of wall (internal) & $.150 \mathrm{~m}$ \\
\hline 10 & Steel Plate Shear Wall & $6 \mathrm{~mm}$ \\
\hline 11 & thickness for each frame & \\
\hline 12 & Soil type & Mediu \\
\hline 13 & Masonry weight & $20 \mathrm{kN} /$ \\
\hline 14 & FF & $2 \mathrm{kN} / \mathrm{m}$ \\
\hline & LL & $4 \mathrm{kN} / \mathrm{m}$ \\
\hline 15 & Earthquake analysis & coefficient \\
& & method \\
\hline 16 & Strips width & $350 \mathrm{~m}$ \\
\hline 17 & Strip angle & $45^{\circ}$ \\
\hline
\end{tabular}

Table 1 : Properties and parameter

ETABS software is used to analyse each building model. Shear wall are modelled in ETABS using Strip modelling. 


\section{Results}

For results column no.1 is selected to compare the result obtained from ETABS software.

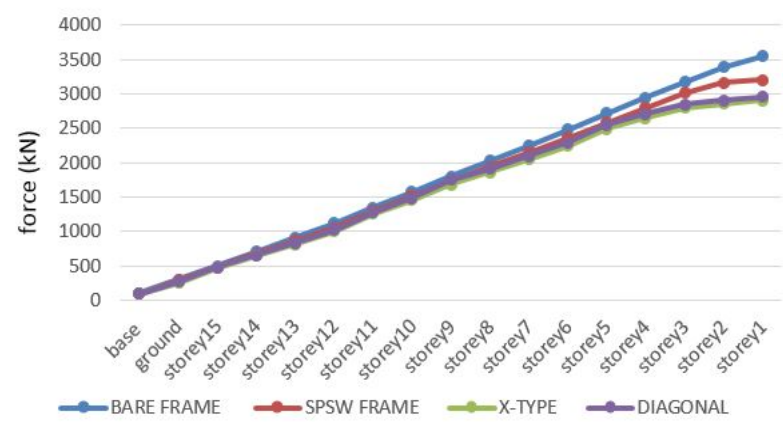

figure 4 : Axial force in column no 1

When a graph is plot for axial force vs storey for different frame. X-type of frame's graph lies at lowest par showing it is the most effective type for SPSW pattern in steel building.

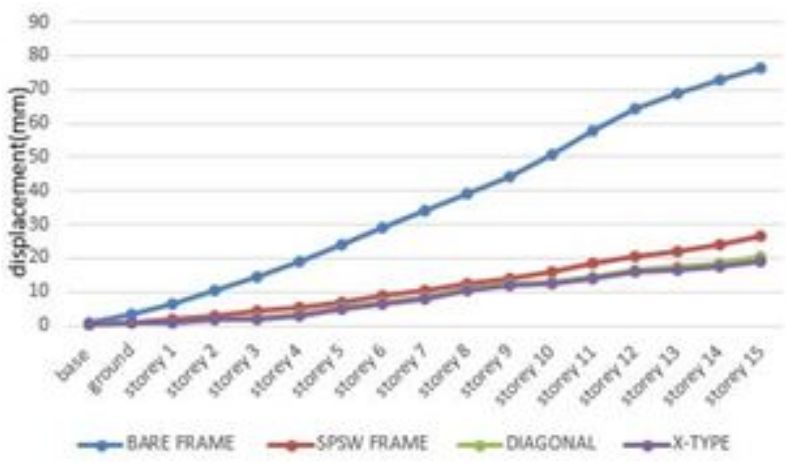

figure 5 : diaplacement in column no 1

Above graph shows that if a graph is plot for displacement vs storey X-type of frame will have lowest curve. Which shows that X-type frame is having lesser displacement among all comparatively

\section{5 conclusion}

After the analysis the following conclusions have been derived:

The maximum displacement in the bare-frame is $76.48 \mathrm{~mm}$. The same for Conventional SPSW frame, Diagonal frame, X-type SPSW are $26.5 \mathrm{~mm}, 20.25 \mathrm{~mm}$ and $18.91 \mathrm{~mm}$ respectively.

Maximum displacement is reduced by $75.27 \%$ in case of X-type shear wall compare to bareframe. 
Axial force at base for bare-frame, Conventional SPSW frame, Diagonal SPSW frame, and Xtype frame is $3540 \mathrm{kN}, 3204 \mathrm{kN}, 2957 \mathrm{kN}$ and $2907 \mathrm{kN}$ respectively. Which is $17.8 \%$ reduction in axial force for X-type compared to bare-frame.

From the above results, it can be observed that axial force for column no. 1 at base in X-type frame is minimum.

From above points, conclusion can be derived as the X-type SPSW is most effective amongst all. Also it is clearly seen that all the different pattern are more effect compare to conventional shear wall.

\section{References}

Jeffrey and Bruneau Michel (November 2003). 'Plastic Analysis and Design of Steel Plate Shear Walls.' Journal of Structural Engineering (C) ASCE.

Topalakati P. and Kinnagi P.M., (2014), 'Parametric Study of Steel Frame Building with and without Steel Plate Shear Wall', Civil and Environmental Research ISSN 2224-5790 (Paper)

Londhe R.S and Chavan A.P (2010), 'Behaviour of building frames with steel plate shear walls' Asian journal of civil engineering (building and housing) vol. 11, no. 1 (2010) Pages 95-102

Verma G. and Maru S., (2013), 'Behavior Of Steel Plate Shear Wall in Earthquake Prone Area: A Review', International Journal of Engineering Trends and Technology (IJETT) - Volume4Issue5May 2013. 